\title{
Anti-CASPR2 antibodies clinical significance and its main phenotypes
}

\author{
Letícia Caroline Breis, Marco Antônio Machado Schlindwein, Marcus Vinicius Magno Gonçalves \\ Department of Medicine, University of the Region of Joinville, Joinville, Santa Catarina 89202-207, Brazil.
}

Correspondence to: Marco Antônio Machado Schlindwein, Department of Medicine, University of the Region of Joinville, Rua Ministro Calogenas, 439, Bucarein, Joinville, Santa Catarina 89202-207, Brazil. E-mail: marcoschlindwein02@gmail.com

\begin{abstract}
How to cite this article: Breis LC, Schlindwein MAM, Gonçalves MVM. Anti-CASPR2 antibodies clinical significance and its main phenotypes. Neuroimmuno/ Neuroinflammation 2020;7:330-4. http://dx.doi.org/10.20517/2347-8659.2020.14
\end{abstract}

Received: 4 Feb 2020 Accepted: 7 Apr 2020 Available online: 6 Jun 2020

Science Editor: Athanassios P. Kyritsis Copy Editor: Jing-Wen Zhang Production Editor: Jing Yu

Contactin associated protein 2 (CASPR2) is cellular adhesion molecule (CAMs) part of the neuroxins family. It is a transmembrane protein with its $\mathrm{C}$-terminal portion interacting with an ankyrin protein called 4.1 B and also a PDZ binding motif ${ }^{[1]}$.

It is localized along the axon, especially in the synaptic terminal and in the juxta-paranodal portion in the node of Ranvier. It is found in neurons on the basal ganglia and other motor areas, limbic system, sensitive pathways, and appears richly expressed in the temporal lobe, especially in inhibitory GAD65 positive neurons ${ }^{[1-3]}$. CASPR2 forms with Contactin-2 part of the VGKC complex, where it has the function of clustering Kv1 channels at the juxta-paranodal ${ }^{[1-3]}$ [Figure 1].

Antibodies against CASPR2 have been described in various forms of clinical presentation ${ }^{[4]}$ [Figure 2], part of this great variation is believed to be associated with great variation in epitopes, although antibodies against the discoidin domain and laminin G1 are found in every patient ${ }^{[1,5,6]}$. As well the overlapping found between peptides of CASPR2 and LGI1 could explain the variation of phenotype when exposure to the same VGKC complex antigens ${ }^{[7,8]}$. Additionally the HLA DRB1 ${ }^{\star} 11: 01$ implicated in CASPR2 is not associated with $\mathrm{LGI}_{1}{ }^{[7]}$.

The pathogenesis in anti-CASPR2 disease is believed to occur due to a block on the interaction between CASPR2 and Contactin-2 ${ }^{[6,9]}$ [Figure 3], and the disrupting the Kv1 channels expression. In some cases, there is reduced expression such as in the dorsal root ganglia ${ }^{[10]}$ and in others inducing an increase 


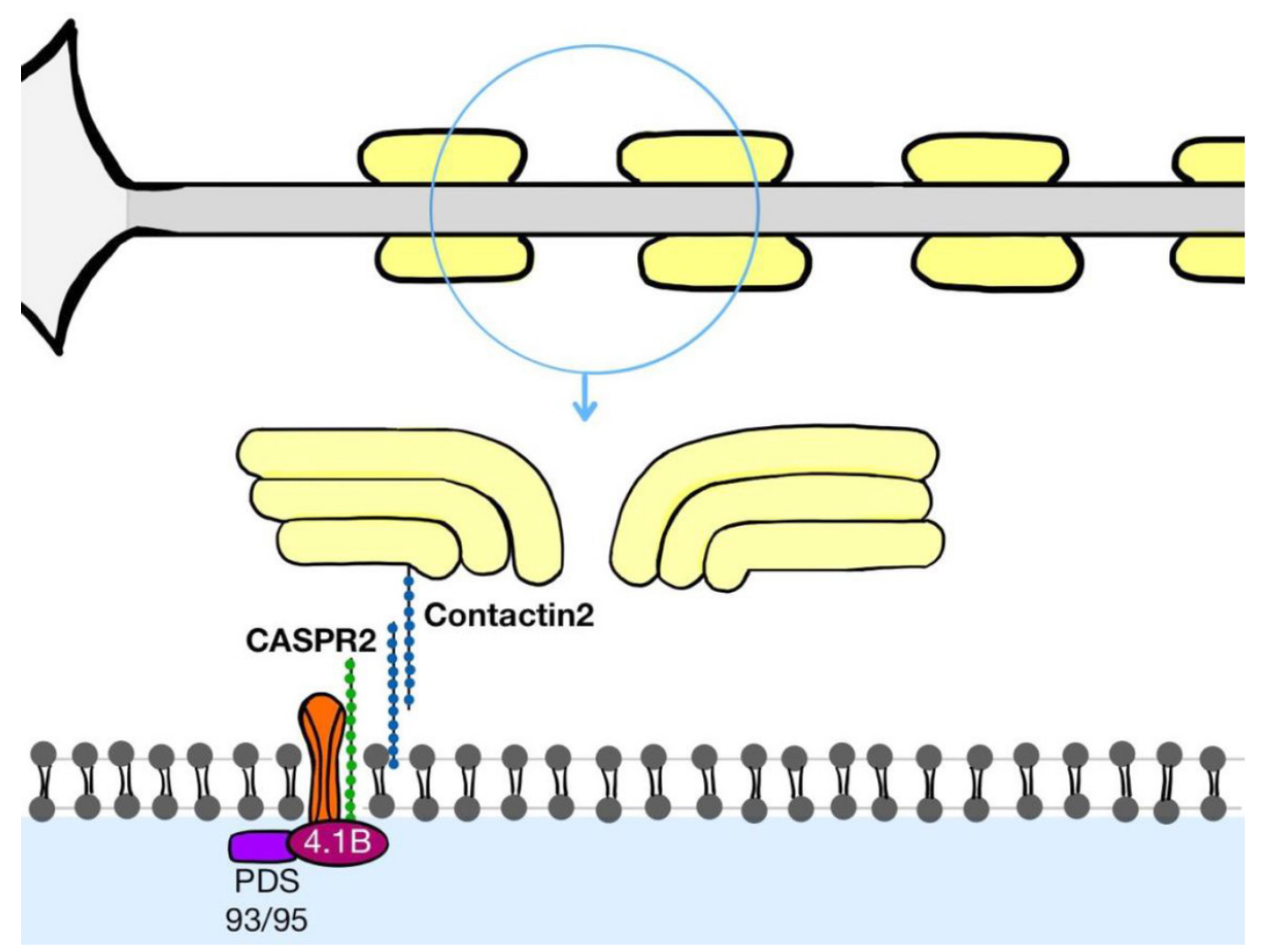

Figure 1. It represents CASPR2 localization at the juxta-paranodal portion in the node of Ranvier, showing its interaction with Contactin-2 forming the voltage gated potassium chanel complex (VGKC complex)

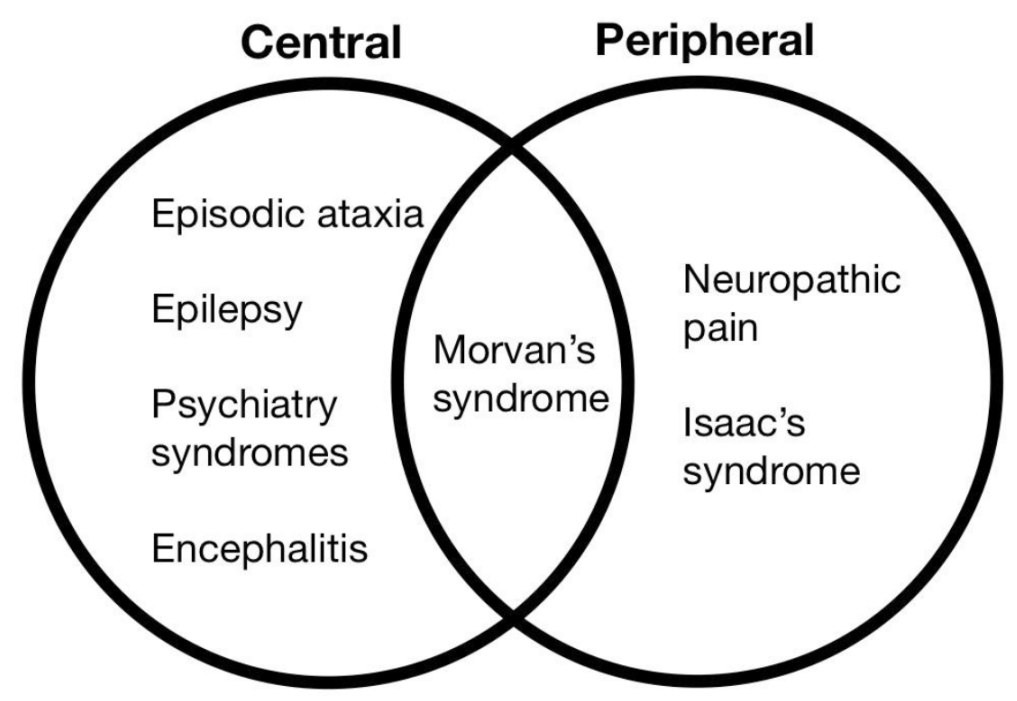

Figure 2. Shows the variety of clinical phenotypes involving the anti-CASPR2 antibodies and it's overlapping between central and peripheral nervous system syndromes

in the expression, especially in the inhibitory interneurons in the hippocampus ${ }^{[6,8,9]}$. This may cause hyperexcitability that could cause epilepsy ${ }^{[8]}$ and network imbalance supported by neuroimaging studies ${ }^{[11]}$.

Morvan's syndrome is an autoimmune disease that affects CNS, PNS and autonomic system ${ }^{[12]}$. It consists of neuromyotonia (cramps, stiffness, fasciculation) ${ }^{[13]}$, encephalopathy, insomnia, dysautonomic signs 


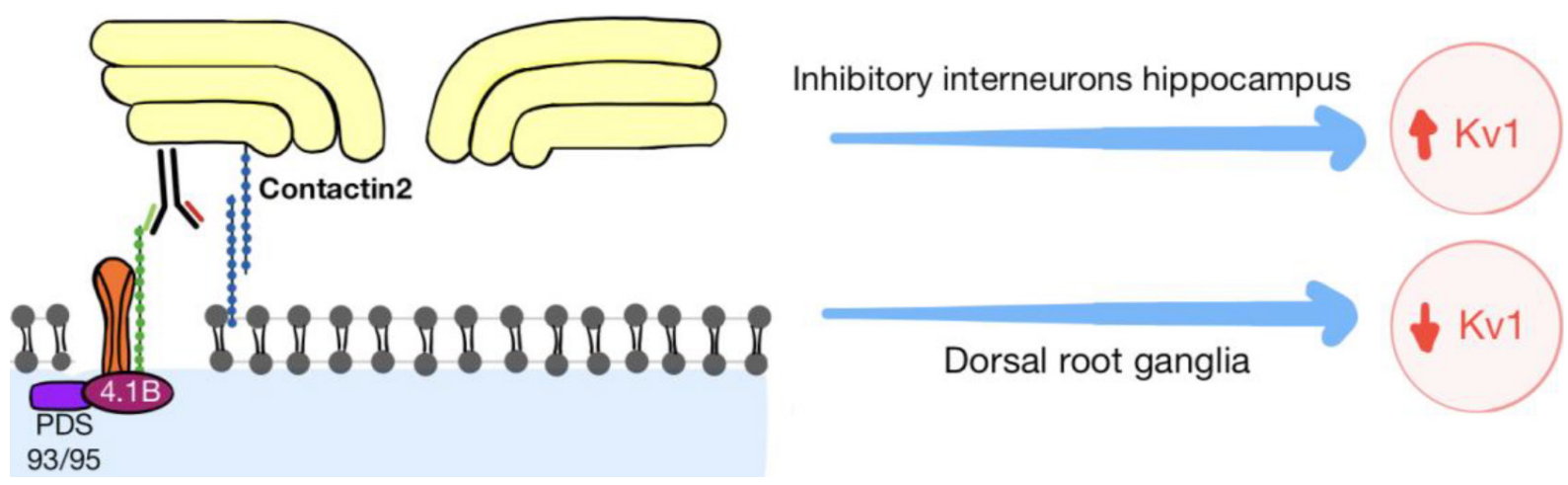

Figure 3. The lgG4 anti-CASPR2 blocking the interaction between CASPR2 and Contactin 2 protein, without activating complement, but disturbing the expression of the voltage gated potassium channel

specially hyperhidrosis and cardiovascular instability, and neuropathic pain ${ }^{[4,13-15]}$. Weight loss, skin lesions or itch, which may result from skin dysautonomia, seizures, fever and SIADH may also be present ${ }^{[12,14]}$.

The largest study investigating Morvan's Syndrome included 29 patients ${ }^{[14]} .93 \%$ of them were male and the median age was 57, varying from 19 to 80 . VGKC-complex antibodies were positive in $79 \%$. Tumor was found in $41 \%$ of the patients, and the most prevalent tumor was thymoma in 11 patients, 9 of them had history of acetylcholine receptor antibodies ${ }^{[14]}$.

Most of the patients have both CASPR2 and LGI1 antibodies ${ }^{[4,15]}$, but CASPR2 antibodies titers are usually higher $^{[14]}$. Antibodies against Contactin-2, a protein expressed in heart conduction tissue, may also be found, associated with cardiovascular instability ${ }^{[14]}$. There are also some patients whose sera are not consistent with CASPR2, LGI1 or contactin-2, increasing suspicion about an unknown antibody ${ }^{[1,16]}$.

Isaac's syndrome is an acquired Peripheral Nerve Hyperexcitability that can include myokymia, muscle cramps, fasciculation, twitching, stiffness, and pseudomyotonia (slow relaxation of the muscles after contraction that happens especially in hands, eyes and jaw ${ }^{[16-18]}$. Muscle activity persists even when the patient sleeps ${ }^{[18]}$ and it may result in muscle hypertrophy ${ }^{[17]}$, mainly calf muscles ${ }^{[16,17]}$, but also forearm and hand muscles Cramps are often worsened by voluntary muscle contraction ${ }^{[17]}$. Dysautonomia (hyperhidrosis, sialorrhea), Trousseau and Chvostek sign may also be present; sensory manifestations are infrequent ${ }^{[16]}$, strength and reflexes are usually normal ${ }^{[17]}$. The symptoms are usually insidious, presenting over years ${ }^{[16]}$.

Antibodies against VGKC complex are found in 38\%-50\% of the patients. VGKC is associated with repolarization of synaptic membranes ${ }^{[12]}$ and its blockage consequently causes nerve excitability ${ }^{[17]}$. Other autoimmune disorders including myasthenia gravis, Addison disease, Hashimoto thyroiditis, are associated, such as neoplasms, mainly thymoma ${ }^{[17]}$. Encephalopathy is not present in Isaac's syndrome ${ }^{[17]}$.

Limbic encephalitis, or limbic encephalopathy, is a reversible cause of cognitive impairment when correctly diagnosed and early treated ${ }^{[19]}$. The main symptoms suggest infectious encephalitis ${ }^{[19]}$, but there are many differential diagnosis besides infection: neurodegenerative dementias, Wernicke-Korsakoff syndrome, Hashimoto's encephalopathy, overdose, schizophrenia and others ${ }^{[4,19]}$. It affects mostly men over 50 years old and has poor association with tumors ${ }^{[4]}$.

The symptoms include amnesia, confusion, psychiatric features, seizures, sleep disturbance and dysautonomia $^{[4,19-21]}$. The presentation vary from acute to insidious ${ }^{[4]}$ and may be preceded by neuromyotonia ${ }^{[22]}$. Focal seizures are the most common type, frequently assuming medial temporal-lobe topography; 
and generalized seizures are less frequent ${ }^{[4]}$. Chandra et al. ${ }^{[19]}$ described 12 patients with anti-VGKC encephalitis; all of them had cognitive decline, sleep disturbance and symptoms of panic, 9 had agitation and 3 had faciobrachial dystonic seizures. Catatonia was observed in anti-NMDA related encephalitis, but not in anti-VGKC ${ }^{[19]}$.

Neuropathic pain is frequently found in patients with CASPR 2 antibodies, likely due to CASPR 2 large expression in peripheral nervous system ${ }^{[13]}$.

CASPR2 antibodies were positive in $10 \%$ of patients with idiopathic ataxia ${ }^{[13]}$. Orthostatism and emotions are triggers to episodic ataxia related to anti-CASPR2 antibodies ${ }^{[23]}$.

First-line therapy consists in steroids, IV immunoglobulin and plasma exchange; while second line consists in rituximab, cyclosporine, mycophenolate mofetil and cyclophosphamide. Immunotherapy leads to better outcomes than no immune therapy ${ }^{[24]}$.

In conclusion, the great variability of syndromes that can be caused by anti-CASPR2 antibodies, despite its rarity, should be remembered in clinical practice as a differential diagnosis of diseases like limbic encephalitis, epilepsy especially in older patients, new onset psychiatry symptoms, neuropathic pain, idiopathic ataxia, because the immunotherapy has been associated with improved outcomes in patients.

\section{DECLARATIONS}

\section{Authors' contributions}

Performed data acquisition and data analysis as well helping with the writing in the text: Breis LC, Schlindwein MAM

Made substancial contribuitions to conception and design of the study, as well as provided technical support: Gonçalves MVM

\section{Availability of data and material}

Not applicable.

\section{Financial support and sponsorship}

None.

\section{Conflicts of interest}

All authors declared that there are no conflicts of interest.

\section{Ethical approval and consent to participate}

Not applicable.

\section{Consent for publication}

Not applicable.

\section{Copyright}

(c) The Author(s) 2020.

\section{REFERENCES}

1. Saint-Martin M, Joubert B, Pellier-Monnin V, Pascual O, Noraz N, et al. Contactin-associated protein-like 2, a protein of the neurexin family involved in several human diseases. Eur J Neurosci 2018;48:1906-23.

2. Arancibia-Carcamo IL, Attwell D. The node of Ranvier in CNS pathology. Acta Neuropathol 2014;128:161-75. 
3. Pinatel D, Hivert B, Saint-Martin M, Noraz N, Savvaki M, et al. The Kv1-associated molecules TAG-1 and Caspr2 are selectively targeted to the axon initial segment in hippocampal neurons. J Cell Sci 2017;130:2209-20.

4. Irani SR, Vincent A. Voltage-gated potassium channel-complex autoimmunity and associated clinical syndromes. Handb Clin Neurol 2016;133:185-97.

5. Olsen AL, Lai Y, Dalmau J, Scherer SS, Lancaster E. Caspr2 autoantibodies target multiple epitopes. Neurol Neuroimmunol Neuroinflamm 2015;2:e127.

6. Saint-Martin M, Pieters A, Déchelotte B, Malleval C, Pinatel D, et al. Impact of anti-CASPR2 autoantibodies from patients with autoimmune encephalitis on CASPR2/TAG-1 interaction and Kv1 expression. J Autoimmun 2019;103:102284.

7. Binks S, Varley J, Lee W, Makuch M, Elliott K, et al. Distinct HLA associations of LGI1 and CASPR2-antibody diseases. Brain 2018;141:2263-71.

8. Romoli M, Krashia P, Sen A, Franciotta D, Gastaldi M, et al. Hippocampal epileptogenesis in autoimmune encephalitis. Ann Clin Transl Neurol 2019;6:2261-9.

9. Koneczny I. A new classification system for IgG4 autoantibodies. Front Immunol 2018;9:97.

10. Dawes JM, Weir GA, Middleton SJ, Patel R, Chisholm KI, et al. Immune or genetic-mediated disruption of CASPR2 causes pain hypersensitivity due to enhanced primary afferent excitability. Neuron 2018;97:806-22.e10.

11. Loane C, Argyropoulos GPD, Roca-Fernández A, Lage C, Sheerin F, et al. Hippocampal network abnormalities explain amnesia after VGKCC-Ab related autoimmune limbic encephalitis. J Neurol Neurosurg Psychiatry 2019;90:965-74.

12. Nikolaus M, Jackowski-Dohrmann S, Prüss H, Schuelke M, Knierim E. Morvan syndrome associated with CASPR2 and LGI1 antibodies in a child. Neurology 2018;90:183-5.

13. Binks SNM, Klein CJ, Waters P, Pittock SJ, Irani SR. LGI1, CASPR2 and related antibodies: a molecular evolution of the phenotypes. J Neurol Neurosurg Psychiatry 2018;89:526-34.

14. Irani SR, Pettingill P, Kleopa KA, Schiza N, Waters P, et al. Morvan syndrome: clinical and serological observations in 29 cases. Ann Neurol 2012;72:241-55.

15. Vale TC, Pedroso JL, Dutra LA, Azevedo L, Filho LH, et al. Morvan syndrome as a paraneoplastic disorder of thymoma with antiCASPR2 antibodies. Lancet 2017;389:1367-8.

16. Sawlani K, Katirji B. Peripheral nerve hyperexcitability syndromes. Continuum (Minneap Minn) 2017;23:1437-50.

17. Ahmed A, Simmons Z. Isaacs syndrome: a review. Muscle Nerve 2015;52:5-12.

18. Song J, Jing S, Quan C, Lu J, Qiao X, et al. Isaacs syndrome with CASPR2 antibody: a series of three cases. J Clin Neurosci 2017;41:63-6.

19. Chandra SR, Ray S, Isaac T, R Pai A, Krishnareddy H, et al. A clinical TRIAD for early suspicion of autoimmune encephalitis as a possibility in patients presenting with progressive cognitive decline. Asian J Psychiatr 2019;41:5-12.

20. Dutra LA, Abrantes F, Toso FF, Pedroso JL, Barsottini OGP, et al. Autoimmune encephalitis: a review of diagnosis and treatment. Arq Neuropsiquiatr 2018;76:41-9.

21. Irani SR, Alexander S, Waters P, Kleopa KA, Pettingill P, et al. Antibodies to Kv1 potassium channel-complex proteins leucine-rich, glioma inactivated 1 protein and contactin-associated protein-2 in limbic encephalitis, Morvan's syndrome and acquired neuromyotonia. Brain 2010;133:2734-48.

22. Montojo MT, Petit-Pedrol M, Graus F, Dalmau J. Clinical spectrum and diagnostic value of antibodies against the potassium channel related protein complex. Neurologia 2015;30:295-301.

23. Joubert B, Gobert F, Thomas L, Saint-Martin M, Desestret V, et al. Autoimmune episodic ataxia in patients with anti-CASPR2 antibodyassociated encephalitis. Neurol Neuroimmunol Neuroinflamm 2017;4:e371.

24. Nosadini M, Mohammad SS, Ramanathan S, Brilot F, Dale RC. Immune therapy in autoimmune encephalitis: a systematic review. Expert Rev Neurother 2015;15:1391-419. 